\title{
Meditation and the scope of mental action
}

\section{Candace L. Upton \& Michael Brent}

To cite this article: Candace L. Upton \& Michael Brent (2018): Meditation and the scope of mental action, Philosophical Psychology, DOI: 10.1080/09515089.2018.1514491

To link to this article: https://doi.org/10.1080/09515089.2018.1514491

曲 Published online: 18 Sep 2018.

Submit your article to this journal $\pi$

View Crossmark data $₫$ 
ARTICLE

\title{
Meditation and the scope of mental action
}

\author{
Candace L. Upton and Michael Brent \\ Department of Philosophy, University of Denver, Denver, CO, USA
}

\begin{abstract}
While philosophers of mind have devoted abundant time and attention to questions of content and consciousness, philosophical questions about the nature and scope of mental action have been relatively neglected. Galen Strawson's account of mental action, the most well developed extant account, holds that cognitive mental action consists in triggering the delivery of content to one's field of consciousness. However, Strawson fails to recognize several distinct types of mental action that might not reduce to triggering content delivery. In this article, we argue that meditation provides a useful model for understanding a wider range of types of mental action than heretofore recognized. Conclusions yielded by two distinct bodies of current psychological research on meditation and cognition, and meditation and introspection, buttress meditation's suitability for this role.
\end{abstract}

\section{ARTICLE HISTORY}

Received 31 August 2017

Accepted 23 May 2018

KEYWORDS

Introspection; meditation;

mental action; mindfulness

\section{Introduction}

Suppose you sit down to meditate. You narrow your attention to focus on the feeling of exhalation on your upper lip, with the goal of clearing from your mind the usual rattle and hum of automatically generated thoughts that typically dominate your conscious field of awareness. Aware of your background, you notice your thoughts drifting away, but you shift your attention back to your breath and maintain this focus, while keeping your mind clear of thoughts. As here characterized, you have performed six different types of mental action: introducing attentional focus, maintaining attentional focus, maintaining awareness of your background, noticing when your attentional focus inadvertently shifts, shifting your attentional focus, and removing content from the mind. However, extant accounts of mental action hold that there is but one type of mental action present.

Strawson (2003) claims that cognitive mental action, understood broadly to include thinking, judging, reasoning, imagining, and choosing, consists in the act of triggering the delivery of content to consciousness. And, in a field 
relatively neglected, Strawson's explanatory framework and his claims about the types and individuation of mental action remain essentially unchallenged. ${ }^{1}$ In this article, we accept the challenge. After providing a brief history of the treatment of mental action by philosophers working in the Anglophone tradition (Section 2), we lay out for the reader three different kinds of meditation and the multiple types of mental action that they involve, and criticize Strawson on one central count (Section 3): He fails to recognize multiple types of mental action that may extend beyond triggering content delivery; and, even if meditation's characteristic act types reduce to mere triggering of content delivery, Strawson's account is incomplete in its failure to recognize several sub-types of mental action that greatly expand our conception of its richness and complexity in practice.

After establishing our initial case against Strawson's account of mental action, we consider two bodies of empirical evidence that support meditation as a useful model for understanding mental action and categorizing its distinct types (Section 4). First, a small body of studies on the cognitive benefits of meditation indicates that meditators actually perform the types of mental action they purport to. Second, given that the types of mental action performed by meditators are underwritten by their first-person reports, we argue that introspection, whose philosophical and psychological underpinnings have been thoroughly maligned, may be more reliable than current orthodoxy indicates. We conclude that meditation serves profitably as a model for understanding the scope and complexity of mental action.

\section{A brief history of mental action}

Mental action has received relatively little attention from contemporary philosophers who discuss questions of agency and mind. In particular, recent philosophical work on consciousness is largely focused on phenomenal consciousness. ${ }^{2}$ Such discussions often highlight the sensory aspects of consciousness having phenomenal properties that determine what it is like to undergo the relevant conscious experience. In such discussions, the typical examples of conscious mental states' possessing phenomenal properties are those frequently assumed to be non-agential, such as perceptual experiences and bodily sensations. The result is that current philosophical accounts of consciousness rarely, if ever, explicitly address mental action. Similarly, philosophical work in action theory tends to overlook the topic as well. For example, three recent anthologies together contain merely two papers that directly discuss mental action. ${ }^{3}$ The scarcity of explicit treatment of mental action should give us pause, if only because so much of our life seems to be engrossed in the performance of mental actions. ${ }^{4}$ 
One reason for such scarcity is skepticism about the extent of our powers of agency within the domain of the mental. One source of this skepticism is recent research in psychology which suggests that much of what happens in consciousness occurs automatically, where conscious mental events are involuntary responses to various internal and external stimuli. ${ }^{5}$ Though this research does not preclude the existence of mental action, it implies that we have far less voluntary control over what takes place in consciousness than we might otherwise believe. Another source of such skepticism is philosophical in origin. The concern here is that the standard explanation of bodily action encounters a serious problem when applied to the mental. According to the standard explanation, an event is an action only if it is initiated and sustained by an intention to perform the relevant type of action. ${ }^{6}$ Now, mental events are individuated in part by their specific content. ${ }^{7}$ For instance, consider a mental event in which the content that the sun is shining becomes present to consciousness. According to the standard explanation of action, this is a mental action only if you intend to think that very thought. But, problematically, this implies that the relevant content must be already present to consciousness in order for its delivery to consciousness to be a mental action.

Drawing on both sources of skepticism, Strawson claims that much of what takes place in consciousness is automatic and beyond our control. ${ }^{8}$ His principal topic is what he describes as "directed thought in general" (Strawson, 2003, p. 230) or "cognition in the widest sense" (Strawson, 2003, p. 244), which primarily includes thinking, judging, reasoning, and belief-formation, but it also encompasses imagining, choosing, and deciding. As he puts it, "mental action in thinking is restricted to the fostering of conditions hospitable to contents' coming to mind. The coming to mind itself - the actual occurrence of thoughts, conscious or non-conscious - is not a matter of action" (Strawson, 2003, p. 234). Crucially, although Strawson describes the act of fostering the relevant cognitive conditions in various ways - as catalyzing, priming, initiating, or triggering - he claims that in each case of thinking, after you have triggered those conditions, content is delivered to consciousness automatically, in a way that you do not control. ${ }^{9}$ Thus, for Strawson, cognitive mental action, broadly understood, is limited to the act of triggering the relevant conditions - the rest is waiting, however briefly, for content to be delivered to consciousness.

In characterizing his account of mental action, Strawson makes two important assumptions that are worth highlighting. First, his claims are supported by his self-conscious awareness of his own experiences while thinking, judging, reasoning, forming beliefs, and so on. That is, in presenting his restrictive account of mental action, he relies on what he describes as "the ordinary experience of thought" (2003, p. 229), which 
involves conscious awareness of a specific feeling, the "sense of control - or origination" (2003, p. 231) or the "sense of intentional authorship" (2003, p. 240) with respect to the delivery of content to consciousness. Crucially, this self-conscious awareness of, and attention to, the way in which content comes to mind is a form of introspection that Strawson uses to draw evidence in support of his skeptical framework. ${ }^{10}$ Second, his claims about our lack of control over the delivery of content to consciousness rely on research in psychology about automaticity. In particular, Strawson cites Libet $(1985,1987,1989)$, Wegner (2002), and Wegner and Wheatley (1999) for empirical support of his claims about the automaticity of content delivery and our lack of control over which content is delivered to consciousness. ${ }^{11}$ Insofar as Strawson's claims about content delivery rest on this psychological research for empirical support, his restrictive account of mental action and skeptical framework stands or falls with the plausibility of this research.

Not everyone is so skeptical. Judging, choosing, deciding, believing, imagining, and remembering are often cited as paradigmatic examples of mental action. For example, Dorsch claims that, "all central cases of imagining consist, essentially and fundamentally, in voluntary actions" (2012, p. 382). Peacocke argues that, "judgements are actions, normally made for reasons" (1999, p. 19). According to Mele, deciding is a mental action when "some mental state ... motivates - causally but not necessarily deterministically - an effort to decide which way to go, which effort is successful" (1997, p. 242). Buckareff suggests that control is exercised over belief by "the mental action of accepting that $p$ " (2004, p. 180). For Owens, our capacity for choice "is under the control of practical judgement in just the way that action (and intention) are under the control of practical judgement" (2009, p. 133). And for Michaelin, remembering is not a matter of passive retrieval of information, but "an active and constructive source of knowledge" (2011, p. 334). How might someone sympathetic to the skeptical view espoused by Strawson explain what happens in such cases, if not as genuine instances of mental action?

In each case, Strawson claims that mental action "is entirely prefatory, it is essentially - merely - catalytic" (2003, p. 231). For instance, when discussing the act of imagining he says that when you entertain imagined content what occurs is "a kind of involuntary response that [you] are prone to experience as action." 12 You are prone to mistakenly experience such events as mental actions, Strawson insists, because they occur involuntarily as a reflexive response to stimuli, typically without felt resistance. Moreover, sustaining and further developing what you imagine can involve mental action, says Strawson, but only of the triggering kind. When referring to judging, choosing, deciding, and remembering, Strawson claims that if we consider the mental events that precede such occurrences, 
we shall see that here too the role of mental action is very restricted. At most, you can deliberately set your mind at the problem requiring that you make a judgment, choice, or decision, thereby focusing your attention on the problem, and such occurrences are mental actions in the form of triggering. But what follows, says Strawson, is again nothing more than a matter of content becoming present to consciousness, which is a matter of a distinctively rational reflex, what he calls the "movement of the natural causality of reason." ${ }^{13}$ In each type of case, after you have triggered the mental event in question, the rest is a matter of ballistics, where the relevant content is delivered to consciousness automatically.

It is undoubtedly correct that you can trigger a mental event in which content is delivered to consciousness as a result, and that in such cases that content has not been intentionally constructed by that very act of triggering. But why, exactly, should we limit our account of mental action in the skeptical way that Strawson does? There is a telling remark that Strawson offers when elaborating his account. He says that "the event of entertaining [content in thought] itself is not an action, any more than falling is once one has jumped off a wall" (Strawson, 2003, p. 235). The idea seems to be that, since falling to the ground occurs because of mechanical forces over which you can exert no direct causal influence, falling cannot be an intentional bodily action that you perform. You merely trigger an event in which you fall, by performing the action of jumping off the wall. ${ }^{14}$ Thus, for Strawson, as far as the bodily action that you perform is concerned, after you have jumped off the wall, the rest is no longer under your control.

Strawson's conception of bodily action is not only controversial but it is undefended. ${ }^{15}$ When describing this notion of action, Strawson cites the work of Davidson, who once claimed that in the case of bodily action, you do nothing more than move your body. ${ }^{16}$ Thus, Strawson assumes that when performing a bodily action you can do nothing more than initiate the movement of your body, so the rationale for the restriction is the assumption that bodily action is limited to just those movements that you are able to bring about directly, without the use of causal intermediaries. ${ }^{17}$ Given this conception of bodily action, when Strawson applies it to the case of the mental, he assumes that you can do nothing more than trigger a process the result of which is a mental event where content is delivered to consciousness; after you have triggered the relevant process, the remainder is out of your control and up to the supposed natural causality of reason.

However, there are plausible alternative ways of understanding intentional actions that do not limit our powers of agency in the way that Strawson assumes is the case. To consider just one example, an account of intentional action inspired by the work of Anscombe would hold that when you jump and fall to the ground, the action in question is to be 
understood in terms of the result that you intend to bring about. ${ }^{18}$ For Anscombe, if falling to the ground is the successful intended result of jumping off the wall, the action in question is not restricted to the mere jumping movement but includes falling to the ground. The action can be identified as such in virtue of your intention to bring about precisely that result by performing the bodily movements in question. It is a non-basic action, one in which you perform an action, falling to the ground, by doing something else, jumping off the wall. In such cases, the required causal intermediaries do not restrict the scope of your powers of agency, and the actions that you can perform are in no way limited to triggering a subsequent event: non-basic action is genuine action, regardless of the presence of causal intermediaries.

Irrespective of whether non-basic mental action counts as mental action proper, though, the study of meditation provides a further challenge to Strawson's understanding of the scope of mental action. As we argue below, meditation endorses several types of mental actions that are not implausibly taken to go beyond merely triggering an event in which content is delivered to consciousness. And even if meditative mental act types do reduce to triggering content delivery, they establish that Strawson's understanding of the richness and scope of mental action is decidedly narrow.

\section{Meditation and the scope of mental action}

Mindfulness and meditation are relative newcomers to the West, but their practice and study have grown dramatically in recent decades. While "mindfulness" and "meditation" show a great deal of conceptual variability, a recent meta-metastudy suggests that both practices are unified by three themes: (1) an action-related theme, (2) a phenomenological theme, and (3) a functional theme. ${ }^{19}$ The action-related theme concerns what the practitioner does, what is under her control, and typically involves a form of self-monitoring wherein she monitors her own thoughts, affective states, and perceptions of her own body and physical environment. By contrast, the phenomenological theme concerns the nature of the practitioner's experience during, and as a result of, meditation, and involves achieving a state of mental silence, wherein the practitioner's self-monitoring precludes the litany of thoughts automatically marching through her conscious experiential field. ${ }^{20}$ Finally, the functional theme concerns the kinds of outcome that may result from achieving a state of (near or complete) mental silence, which include self-regulation of cognitive states, affective states, and behavior. Since virtually all forms of mindfulness and meditation involve at least one element from each of these three themes, we shall henceforth treat both practices as univocal. ${ }^{21}$ 
Two distinct forms of self-monitoring are crucial to understanding the nature of meditation and its bearing on the nature and scope of mental action: Focused Attention Monitoring (FAM) and Open Awareness Monitoring (OAM). When practicing FAM, the meditator focuses her attention upon some aspect of her experiential field. If seated, she might focus on the feeling of exhalation on her upper lip, a candle flame, or a mantra that she silently repeats to herself. If standing or in motion, as in yoga or tai chi, she might focus on the delivery of proprioception, the sense of how her body is located in space, by focusing on the feeling of her muscles and her joints' interrelations. Either way, the practitioner's explicit aim is to maintain her focus of attention, which may remain either stable on one item, or shifting, such that her focus shifts from one item to another. While maintaining her attentional focus, the meditator must also maintain an awareness of the other items in her field of conscious experience, whether they be cognitive, affective, visual, aural, muscular, sensory, or other. For she must be able to notice when her attentional focus has waned and her thoughts begin to wander, whereupon she must disengage from the errant object of thought and shift her attention back to the original item(s) of focus.

When practicing OAM, the meditator aims to maintain an awareness of some aspect(s) of her experiential field, yet without focusing on any item(s) within that field. She might maintain awareness of her perception of her body, her perception of the physical environment she inhabits, her cognitive and affective states, or on perceptions from any combination of these experiential fields. But, as soon as she notices that she has begun to focus on an item, or that her awareness has shifted outside her selected domain, she must retract her focus or wandering awareness and shift her awareness to her (chosen) experiential state(s).

In both cases, the meditator's explicit goal is to achieve a state of mental silence, wherein she does not experience the litany of automatically generated thoughts. ${ }^{22}$ When the focused attention meditator successfully focuses her attention on an item (or items), she thereby precludes her experience of the constant, automatically generated cognitive activity. Similarly for the open awareness meditator, when she successfully monitors her experiential states, she thereby precludes her experience of the constant, automatic cognitive activity.

Achieving a state of mental silence can be exceedingly frustrating for the novice meditator. For the typical beginner, attentional focus is easily, regularly, and persistently interrupted by the automatic march of thoughts through consciousness. It takes great effort to notice that one's focus on her breath elides into a long string of thoughts about how delightful that sandwich was, how ominous that knocking sound in the car is, and how many errands she still needs to run. But, when she notices, she shifts her attentional focus 
back to her breath, to the preclusion of the automatically generated thoughts. As the so-called automatic thought generator continues to interrupt her selffocus, she must exert effort to maintain self-focus. However, as the practitioner continues to meditate and improves her ability to maintain self-focus, the effort she must exert to maintain a state of focus dissipates significantly. Importantly, neurological differences between novice and expert meditators are apparent: the density of expert meditators' grey matter in the right anterior insula, a region independently associated with interoceptive awareness (Holzel et al., 2008), is significantly enhanced.

Before describing the different types of mental action the meditator performs, it is important to note one other form of meditation, Loving Kindness Meditation (LKM), which has a cognitive and an affective form. In practicing the cognitive form of LKM, the practitioner silently repeats thoughts of love, kindness, and goodwill to her loved ones; later, she directs these thoughts toward friends, acquaintances, and strangers; finally, she directs these thoughts toward those for whom she has negative thoughts and feelings. In practicing the affective form of LKM, the practitioner imagines the affective state that typically accompanies thoughts of love, kindness, and goodwill toward those she loves; later, she isolates that affective state, yet directs it toward friends, acquaintances, and strangers; finally, she directs the affective state toward those for whom she has negative thoughts or feelings. ${ }^{23}$

Let us consolidate the different kinds of mental action the meditator performs. First, while engaging in FAM, both shifting and stable, the meditator:

- Introduces attentional focus

- Maintains her attentional focus

- Shifts her attentional focus (if engaging in shifting FAM)

- Maintains awareness of her background

- Notices when/if her focus has shifted from her chosen positive anchor(s)

- Shifts her focus back to the chosen positive anchor, and thereby

- Removes automatically generated cognitive content

And, while engaging in OAM, the meditator:

- Removes focus

- Notices when/if her monitoring becomes distracted

- Shifts back to a state of awareness with no focus within her chosen field, and thereby

- Removes automatically generated cognitive content

Next, while engaging in the cognitive form of LKM, the meditator: 
- Introduces cognitive content and

- Removes content

And, finally, while engaging in the affective form of LKM, the meditator:

- Introduces an affective state

- Removes an affective state and she may

- Intensify an affective state or

- De-intensify an affective state

In sum, the meditator may perform any of the following mental actions:

(1) Introduce attentional focus

(2) Maintain attentional focus

(3) Shift attentional focus (in shifting FAM)

(4) Maintain awareness of background

(5) Notice when/if her focus inadvertently shifts from her anchor(s)

(6) Remove focus

(7) Notice when/if open monitoring becomes distracted (in OAM)

(8) Introduce content

(9) Remove content

(10) Introduce an affective state

(11) Remove affective state

(12) Intensify an affective state

(13) De-intensify an affective state

Strawson provides several examples of mental actions, each of which allegedly involves nothing more than triggering the delivery of content to consciousness. ${ }^{24}$ For instance, he claims that priming can be a mental action whereby you direct your mind at the problem at hand, perhaps by refreshing images of a scene or rehearsing inferential transitions; shepherding can be a mental action in which you bring your wandering mind back to the relevant content; blanking can be a mental action in which you bring about a clearing of the mind by suppressing unwanted content; attending can be a mental action whereby you direct and maintain the focal point of attention upon the relevant content. ${ }^{25}$

Interestingly, however, priming, shepherding, blanking, and attending are mental actions that are endorsed by FAM. As Strawson characterizes it, priming (i.e., directing your mind at the problem at hand) involves shifting and maintaining your attentional focus. While refreshing images of a scene and rehearsing inferential transitions do involve delivering content to consciousness, directing your mind at the relevant problem requires shifting your attentional focus, noticing when your attentional focus has 
shifted, and maintaining that focus overtime. Shepherding (i.e., bringing your wandering mind back to the relevant content), too, involves noticing when your attentional focus has shifted, shifting your attentional focus, and maintaining that focus overtime. In addition, while bringing your wandering mind back to the relevant content may involve delivery of content to consciousness, it also involves removal of content, as does blanking. Clearing the mind involves removal of content and is achieved by maintaining attentional focus. Attending (i.e., directing and maintaining the focal point of attention upon the relevant content) explicitly involves introducing and maintaining focus.

From examining these act types alone, it is clear that Strawson's account is incomplete insofar as it fails to include several species of mental act types, including removing focus, noticing when open monitoring becomes distracted, maintaining awareness of one's background, introducing and removing an affective state, and intensifying or de-intensifying an affective state. $^{26}$ It is unclear, however, whether meditative mental act types reduce to triggering the delivery of content to consciousness. If they do so reduce, then Strawson is right that all cognitive action involves triggering content. If they do not, however, then Strawson must endorse a further genus of mental act types not involving triggering the delivery of content. Let us examine the putative reducibility of meditative mental action types in order of their susceptibility to reduction:

First, of the 13 types of mental action enumerated above, those that explicitly reduce to content delivery include \#3 (shifting focus), \#8 (introducing content), and \#10 (introducing an affective state).

Second, mental acts \#5 (noticing that focus shifts) and \#7 (noticing that open monitoring becomes distracted) likely reduce to content delivery. Noticing is likely a complex meta-cognitive act, wherein I cognitively introduce a standard/constraint that my focus (or open monitoring) must satisfy and introduce meta-attention over the domain of my focus (or monitoring). If these two cognitive actions are performed properly and I maintain both my awareness of the standard and my meta-attention, then I will automatically notice that my focus (or open monitoring) has shifted, in a fashion analogous to visual perception. The mental actions I perform that are relevant to noticing involve introducing a standard that my focus must satisfy and introducing metaattention. Noticing that one's focus has shifted (or that one's open monitoring has become distracted) is not a separate mental act. Thus, independent of a distinct account of noticing, noticing that focus shifts and noticing that open monitoring becomes distracted are reducible to delivery of content.

Third, it is epistemically open at present whether mental act types \#12 (intensifying affective state) and \#13 (de-intensifying affective state) reduce to 
content delivery. Suppose I introduce the affective state associated with love and then proceed to intensify that state. While the initial feeling of love that I produce is qualitatively identical to the subsequent, slightly-more-intense feeling of love that I produce, one is felt more strongly. But whether different representational content is delivered to consciousness depends on whether one is an internalist or externalist about content individuation, the adjudication of which far exceeds the scope of this article.

Fourth, it is similarly open whether mental act types \#1 (introducing attentional focus) and \#6 (removing attentional focus) count as acts of triggering content delivery. Typical cases of attending enable the subject to render the focused-upon item suitable for recollection of detail, such as cases wherein I, say, direct my attention to a particular auditory sensation; introducing focus trains a metaphorical spotlight on the relevant item in consciousness. Prior to introducing focus, I was aware of the auditory sensation, but could not describe its detail at any important level of specificity. But, whether new representational content has been delivered to consciousness as a result of attending to that auditory sensation depends on one's account of content, which is, again, far beyond the scope of this article. Hence, we treat the reducibility of act types $\# 1, \# 6, \# 12$, and \#13 as open.

Fifth, act types \#2 (maintaining attentional focus) and \#4 (maintaining awareness of background) plausibly resist reduction to content delivery, depending upon whether maintaining awareness and maintaining focus involve continual, repeated acts of content delivery. ${ }^{27}$ Clearly, if the meditator gets distracted and loses her focus (or awareness), upon noticing the distraction, she refreshes. However, it might be only novice meditators who encounter the need to refresh (given their distracted attention), while expert meditators often do not need to. Further, the phenomenal experience of undistracted maintenance of focus and/or awareness of background, especially for expert meditators, indicates that token meditative actions of maintaining attentional focus and background are continuous, rather than a collection of discrete acts.

Finally, meditation act types \#9 (removing content) and \#11 (removing an affective state) likely resist reduction to content delivery. If one removes content (or an affective state) merely by replacing it with distinct content, then removing content clearly reduces to content delivery. However, if one removes content (or an affective state) by introducing attentional focus (and thereby introducing a state of mental silence), as FAM indicates, removing content and removing an affective state are not reducible. ${ }^{28,29}$

To conclude, three types of meditative mental action (\#3, \#8, \#10) explicitly reduce to content delivery. Two meditative mental act types (\#5, \#7) likely reduce to content delivery, depending on one's account of noticing. Four meditative act types' (\#12,\#13, \#1, \#6) putative reducibility 
is open and depends upon one's account of content. Two meditative act types (\#2, \#4) probably resist reduction, depending on whether expert meditators whose attention/awareness does not get distracted need to refresh their attention. And two further meditative act types (\#9, \#11) plausibly resist reduction, provided meditators can remove content by introducing a state of mental silence.

We cannot rule out that some non-meditative practice might serve as an equitable or superior guide to mental action. And some meditative practices seemingly do not contribute to our understanding of mental action: Zen meditation, for example, requires practitioners to introduce one kind of content (reflection on koans - mantras involving contradictions, typically) to achieve a state of cognitive silence. However, with respect to understanding and categorizing mental action, meditation is particularly apt for highlighting the subtleties and complexities of the various types of mental action that exist, especially given the relative difficulty of performing such actions, which makes them all the more likely to be overlooked or not performed at all. Further, after 20 years of fruitful psychological research on meditation, philosophical study of the practice arrives well-equipped with a rich body of relevant empirical data ready to be harvested, analyzed, and such by moral psychologists, epistemological psychologists, and more.

We have established a prima facie case against Strawson's account of mental action: he fails to recognize meditation as providing a model for the different types of mental action we are capable of performing, and he fails to recognize that some types of meditative mental action plausibly resist reduction to the triggering of content to consciousness. In the following section, we establish a prima facie case in support of meditation as a guide to the scope of mental action.

\section{The psychological evidence}

If the thesis of this article is correct, meditation provides a model for understanding and categorizing mental action, the scope of which might extend beyond triggering content to consciousness. Thus far, we have argued that mental action includes introducing and removing content, introducing, removing, intensifying, and reducing the intensity of affective states, introducing, shifting, maintaining, or removing attentional focus, maintaining awareness of one's background, and noticing when attentional focus or open monitoring become distracted.

However, two related challenges might be raised. First, the most direct evidence supporting the claim that meditators actually perform the mental actions characteristic of FAM, OAM, and LKM comes in the form of introspection. But, both philosophers and psychologists have long denigrated the epistemic reliability of introspection. Second, one might 
question whether there is any empirical evidence, beyond the introspective, that meditators actually perform the types of mental actions characteristic of FAM, OAM, and LKM.

The central evidence available that meditators actually perform a variety of mental action types during meditation relies upon first-person reports of their inner experience and, so, relies upon the accuracy and reliability of introspection. But, Nisbett and Wilson's searing and sweeping arguments against the veracity of introspection are well-known: "The accuracy of subjective reports is so poor as to suggest that any introspective access that may exist is not sufficient to produce generally correct or reliable reports" (1977, p. 233). Less well-known are Nisbett and Wilson's caveat to their own conclusion: “...the studies do not suffice to show that people could never be accurate about the processes involved. To do so would require ... theoretically interesting procedures such as interrupting a process at the very moment it was occurring, alerting subjects to pay careful attention to their cognitive processes, coaching them in introspective procedures, and so on" (1977, p. 246). In fact, this is precisely the direction in which much psychological research on introspection is heading.

Current psychological research on meditation and introspection suggests promising results. Hurlburt and Heavey's (2001, 2004) psychological research on introspective veracity involves interrupting cognitive processes as they occur, alerting subjects to pay careful attention to their cognitive states, and coaching them in introspective procedures, thereby satisfying the criteria Nisbett and Wilson posit for the reliable study of introspection. Second, Hill and Updegraff (2012) conclude that meditators experience greater clarity about what emotions are felt. Third, Baird, Mrazek, Phillips, and Schoolar (2014) conclude from one study that "the human capacity to introspect [in the domain of memory] is plastic and can be enhanced through training." Fourth, Fox and colleagues conclude that "[e]xpert meditators showed significantly better introspective accuracy than novices" in subjective reports of tactile sensitivity $(2012$, p. 1$) .{ }^{\mathbf{3 0}}$

While this body of empirical study is far from robust, it has the advantage of studying not only subjects' first-person reports of their mental states but also the neurological underpinnings of those mental states, such that these two classes of data can be correlated with one another. For these reasons, the empirical research is at least suggestive that the practice of meditation enhances particular introspective capacities; further study will hopefully confirm this suggestion.

In addition, a robust and growing body of psychological evidence on cognition indicates that meditation actually does enable us to develop and perform the different types of mental action involved in meditation. Meditation enhances orienting (bringing an item to one's attentional focus), alerting (detecting targets outside one's attentional focus), conflict monitoring (prioritizing among conflicting stimuli), attentional blink 
(distributing attentional resources), and disengaging (not pursuing or acting upon the automatic deliverances of the "tape recorder" in the mind). Jha, Krompinger, and Baime (2007) conclude that meditation enhances orienting among novice practitioners and enhances alerting and conflict monitoring among experienced practitioners. Slagter et al. (2007) conclude that meditation leads to an increase in attentional resources. MacLean et al. (2010) conclude that meditation enhances the duration over which one can maintain her attentional focus. And, Van Vugt (2015) concludes that meditation enables us to disengage from the parade of thoughts, images, and such that automatically and nearly constantly occupy consciousness.

This small, albeit telling, body of empirical evidence is sufficient to establish a prima facie case in support of meditation as a model for understanding and categorizing different types of mental action. In sum, the most recent empirical studies on introspection suggest promising results. Moreover, empirical studies whose methodologies do not appeal to subjects' introspective reports indicate that meditators do, in fact, develop the relevant attention- and awareness-based cognitive skills.

\section{Concluding remarks and looking ahead}

Historically, philosophical questions about the nature and scope of mental action have received insufficient attention. And, Strawson's restrictive account of mental action, the most well developed extant account, does not explain the variety of types of mental action that exist. In its stead, we suggest that meditation provides a useful model for understanding and categorizing a variety of types of mental actions. Conclusions yielded by two bodies of psychological research further support the suitability of meditation for this role. However, much work remains to be done.

First, although we have appealed to meditation as a model for understanding and categorizing types of mental action, we have not here offered a general account or definition of mental action, or provided necessary and sufficient conditions for something to be a mental action, or proposed a criterion for distinguishing between mental actions and mere mental events. In particular, we have here offered no explanation of how we perform mental actions in general. A comprehensive account of mental action must explain how, exactly, the meditator exerts control over her attentional focus, or the intensity of her affective states, or the content that she brings to or removes from consciousness. Second, we have nonchalantly assumed that the notion of the meditator as an agent who performs a variety of mental actions is uncontroversial. A complete account of mental action must provide an explanation of the metaphysical category to which the meditator belongs. What conception of the meditator qua 
agent best explains the different types of mental action introduced and discussed here? Third, given the evidence that suggests that our skills at introspection can be improved through training and practice, what then should we say about the relation(s) between the phenomenology of consciousness and the ontology of mind? For instance, is it plausible to conclude that, even if only for the skilled meditator, the phenomenology of conscious experience provides access to truths about consciousness? While these fascinating questions remain open at present, we eagerly await future philosophical and psychological research on the nature and scope of mental action, the nature of the meditator qua agent, and the nature of the relation between the phenomenology of and truths about consciousness.

\section{Notes}

1. Exceptions include Boyle (2009, 2011), Buckareff (2004), Buckareff $(2005,2007)$, Latham (2016), Levy (2016), Mele (1997, 2009), O’Brien and Soteriou (2009), Peacocke (2007), Proust (2001, 2013), Ruben (1995), Shepherd (2015), Soteriou (2013), Strawson (2003), Valaris (2017), Watzl (2017), and Wu (2013). The centrality of Strawson's account is attested by the fact that, other than those published prior to (Strawson, 2003) and Peacocke (2007), each of the aforementioned papers address Strawson (2003).

2. See the extensive literature inspired by Chalmers (1996), Dennett (1991), Dretske (1995), Jackson (1982), Nagel (1974), and Searle (1980), among others.

3. See Aguilar, Buckareff, and Frankish (2011) and Dancy and Sandis (2015). The former has 12 papers of which a single entry addresses the topic, and the latter is comprised of 37 papers, none of which directly address mental action. Of the 75 entries in O'Connor and Sandis (2010), only one discusses the notion of mental acts.

4. This echoes Stocker (1982, p. 398), who says "Indeed, were there no mental activity, were people not active and responsible for what they think and believe, then what possibly and what in good conscience are we doing teaching, writing, discussing, and the like - in doing philosophy?" .

5. The roots of contemporary psychological research on automaticity can be traced to Kahneman (1973) and Schneider and Shiffrin (1977). More recent research includes Bargh (1994) and Bargh and Chartrand (1999). For an overview see Evans (2010).

6. Defenders of the standard explanation of bodily action include Bishop (1989), Brand (1984), Bratman (1987), Davidson (1963), Enç (2003), Goldman (1970), and Mele (1992), among many others.

7. The relevant notion of content is that of conscious representational content. It is non-committal with regard to its status as conceptual, non-conceptual, or mixed.

8. See Strawson (2003).

9. For descriptions of different ways that fostering might occur, see Strawson (2003, pp. 231-232).

10. Strawson is careful not to use the term "introspection"; we briefly discuss introspection in Sections 3-4.

11. See Strawson (2003, p. 246, note 41). For criticism of the relevant empirical literature, see Bayne (2006) and Mele (2009). 
12. See Strawson (2003, p. 239). Wu (2013, esp. Section 7) makes a similar remark.

13. See Strawson (2003, p. 244). The notion of the natural causality of reason is not clarified, but it seems to be akin to what Hume (1748/1999) dubbed the 'Principles of Association' among ideas, as what explains which content comes to mind.

14. See also Strawson (2003, p. 241, note 33), where he says that the motion of your leg after you have initiated a kick is "merely ballistic - as ballistic as the motion of the ball after it has ceased to be in contact with one's foot." Here, the idea is that kicking the ball is not an action that you perform. Rather, your action just is triggering the relevant motion of your leg, while the remainder is out of your control.

15. The controversy surrounding this conception of bodily action was widely discussed under the guise of the problem of action-individuation. See, for example, Goldman (1971) and Jarvis Thompson (1971).

16. See Davidson (1971). Notably, Davidson later changed his mind. For discussion, see Davidson (1978).

17. This is why Strawson says that there are reasons for drawing the line between intentional actions and what merely happens further in than Davidson (1971) does. See Strawson (2003, p. 245, note 39), where he says that the line might be drawn inside the brain. If this were correct, all intentional action would consist in triggering cerebral events. The similarity between this and a view of agent causation once defended by Roderick Chisholm is striking. See Chisholm (1964/2003).

18. See Anscombe (1957/2000). Note that we do not here defend Anscombe's account of action. Rather, we offer her view as an alternative to Strawson's, to show that his is neither mandatory nor uncontroversial.

19. This understanding of meditation is adapted from Upton (2017).

20. This characterization of meditation is more apt of Western forms, rather than Eastern. See for further discussion.

21. Of course, there is a great deal of richness that this characterization of mindfulness and meditation glosses over.

22. It is an empirical question whether meditation swamps the relevant neurophysical mechanism's typical manifestation, or precludes its functioning at all.

23. The functional goal of LKM is to enable practitioners to regulate their (cognitiveaffective state of) resentment of and dislike for others, not to achieve a state of mental silence.

24. See Strawson (2003, pp. 231-232).

25. Importantly, Strawson claims that priming, shepherding, blanking, and attending "can be matter[s] of action" (p. 232), implying that one could come either passively or actively to hold these states; only the latter involves mental action proper.

26. With all due credit to Strawson, his thesis seemingly applies to all (and only) cognitive actions (broadly construed). Since introducing, removing, intensifying, and de-intensifying an affective state are not cognitive actions, it is not a proper objection to Strawson's account that it excludes these action types.

27. Strawson suggests this option. See Strawson (2003, p. 232, note 14).

28. Note that however one removes content (and affective states, more specifically), either by introducing distinct content or introducing focus, one's mental action is non-basic. This presents a potential problem for Strawson, who rejects the claim that non-basic mental actions are mental actions (proper), but also espouses blanking (removing content) via suppressing unwanted content, which is not implausibly taken to be a non-basic action.

29. Thanks to an anonymous reviewer for suggesting how the putative reduction of 2 and 4 , and 9 and 11, to triggering content delivery might operate. 
30. Research psychologists are also currently working at amassing a body of literature on the breadth of introspection's veracity (considered independent of meditation and mindfulness). For example, see Reyes and Sackur (2014, 2017a, 2017b).

\section{Acknowledgments}

We are grateful to two anonymous reviewers, whose insightful comments helped significantly to improve this article. For helpful discussion and advice, M.B. would like to thank Santiago Arango, Maria Doulatova, James Dow, Alex Grzankowski, David Hunter, Robert Kurzban, Neil Levy, Jorge Morales, Jennifer Nagel, Marco J. Nathan, Nicholas Ravnikar, Naomi Reshotko, Gabriel Reyes, Juan Pablo Bermúdez Rey, Jere Surber, Sebastian Watzl, and Wayne $\mathrm{Wu}$.

\section{Disclosure statement}

No potential conflict of interest was reported by the authors.

\section{Notes on contributors}

Candace L. Upton is an Associate Professor of Philosophy at the University of Denver. She specializes in moral psychology, virtue ethics, ethical theory, metaphysics, and logic

Michael Brent is an Assistant Professor of Philosophy at the University of Denver, working in metaphysics, philosophy of action, and philosophy of mind.

\section{References}

Aguilar, J., Buckareff, A., \& Frankish, K. (Eds). (2011). New waves in philosophy of action. New York, NY: Palgrave Macmillan.

Anscombe, G. E. M. (1957/2000). Intention (2nd ed.). Cambridge, MA: Harvard University Press.

Baird, B., Mrazek, M. D., Phillips, D. T., \& Schoolar, J. W. (2014). Domain-specific enhancement of metacognitive ability following meditation training. Journal of Experimental Psychology: General, 143, 1972-1979.

Bargh, J. A. (1994). The four horsemen of automaticity: Intention, awareness, efficiency, and control in social cognition. In R. S. Wyer \& T. K. Srull (Eds.), Handbook of social cognition (2nd ed., pp. 1-40). Hillsdale, NJ: Erlbaum.

Bargh, J. A., \& Chartrand, T. L. (1999). The unbearable automaticity of being. American Psychologist, 54(7), 462-479.

Bayne, T. (2006). Phenomenology and the feeling of doing: Wegner on the conscious will. In S. Pockett, W. P. Banks, \& S. Gallagher (Eds.), Does consciousness cause behavior? (pp. 169-186). Cambridge, MA: MIT Press.

Bishop, J. (1989). Natural agency: An essay on the causal theory of action. New York, NY: Oxford University Press.

Boyle, M. (2009). Active belief. Canadian Journal of Philosophy, 39(S1), 119-147.

Boyle, M. (2011). 'Making up your mind' and the activity of reason. Philosophers' Imprint, 11(17), 1-24. 
Bratman, M. E. (1987). Intentions, plans and practical reason. Cambridge, MA: Harvard University Press.

Brand, M. (1984). Intending and acting: Towards a naturalized action theory. Cambridge, MA: The MIT Press.

Buckareff, A. A. (2005). How (not) to think about mental action. Philosophical Explorations, 8(1), 83-89.

Buckareff, A. A. (2007). Mental overpopulation and mental action: Protecting intentions from mental birth control. Canadian Journal of Philosophy, 37(1), 49-65.

Buckareff, A. A. (2004). Acceptance and deciding to believe. Journal of Philosophical Research, 24, 173-190.

Chalmers, D. (1996). The conscious mind. New York, NY: Oxford University Press.

Chisholm, R. (1964/2003). Human freedom and the self. In G. Watson (Ed.), Free Will. New York, NY: Oxford University Press.

Dancy, J., \& Sandis, C. (Eds). (2015). Philosophy of action: An anthology. London, UK: Wiley-Blackwell.

Davidson, D. (1963). Actions, reasons and causes. The Journal of Philosophy, 60(23), 685-700.

Davidson, D. (1971). Agency. In R. Binkley, R. Bronaugh, \& A. Marras (Eds.), Agent, action, and reason. Toronto: University of Toronto Press.

Davidson, D. (1978). Intending. In Y. Yovel (Ed.), Philosophy of history and action. Dordrecht: D. Reidel.

Dennett, D. C. (1991). Consciousness explained. Boston: Little, Brown, \& Co.

Dorsch, F. (2012). The unity of imagining. Berlin: De Gruyter.

Dretske, F. (1995). Naturalizing the mind. Cambridge, MA: The MIT Press.

Enç, B. (2003). How we act: Causes, reasons, and intentions. New York, NY: Oxford University Press.

Evans, J. S. B. T. (2010). Thinking twice: Two minds in one brain. New York, NY: Oxford University Press.

Fox, K. C. R., Zakarauskas, P., Dixon, M., Ellamil, M., Thompson, E., \& Christoff, K. (2012). Meditation experience predicts introspective accuracy. PLoS ONE, 7.

Goldman, A. (1970). A theory of human action. Englewood Cliffs, NJ: Prentice Hall.

Goldman, A. (1971). The individuation of action. Journal of Philosophy, 68(21), 761-774.

Hill, C. L. M., \& Updegraff, J. A. (2012). Mindfulness and its relationship to emotion regulation. Emotion, 12, 81-90.

Hölzel, B. K., Ott, U., Gard, T., Hempel, H., Weygandt, M., Morgen, K., \& Vaitl, D. (2008). Investigation of mindfulness meditation practitioners with voxel-based morphometry. Social Cognitive and Affective Neuroscience, 3, 55-61.

Hume, D. (1748/1999). Enquiries concerning human understanding (T. L. Beauchamp, Ed.). Oxford: Oxford University Press.

Hurlburt, R. T., \& Heavey, C. L. (2001). Telling what we know: Describing inner experience. Trends in Cognitive Sciences, 5, 400-403.

Hurlburt, R. T., \& Heavey, C. L. (2004). To beep or not to beep: Obtaining accurate reports about awareness. Journal of Consciousness Studies, 11, 113-128.

Jarvis Thompson, J. (1971). Individuating actions. Journal of Philosophy, 68(21), 774-781. Jackson, F. (1982). Epiphenomenal qualia. Philosophical Quarterly, 32, 127-136.

Jha, A. P., Krompinger, J., \& Baime, M. J. (2007). Mindfulness training modifies subsystems of attention. Cognitive, Affective, and Behavioral Neuroscience, 7, 109-119.

Kahneman, D. (1973). Attention and effort. Englewood Cliffs, NJ: Prentice-Hall.

Latham, N. (2016). Meditation and self-control. Philosophical Studies, 173(7), 1779-1798.

Levy, Y. (2016). Action unified. The Philosophical Quarterly, 66(262), 65-83. 
Libet, B. (1985). Unconscious cerebral initiative and the role of conscious will in voluntary action. Behavioral and Brain Sciences, 8, 529-566.

Libet, B. (1987). Are the mental experiences of will and self-control significant for the performance of a voluntary act? Behavioral and Brain Sciences, 10, 783-786.

Libet, B. (1989). The Timing of a subjective experience. Behavioral and Brain Sciences, 12, 183-185.

MacLean, K. A., Ferrer, E., Aichele, S. R., Bridwell, D. A., Zanesco, A. P., Jacobs, T. L., \& Saron, C. D. (2010). Intensive meditation training improves perceptual discrimination and sustained attention. Psychological Science, 21, 829-839.

Mele, A. (1992). Springs of action. Oxford: Oxford University Press.

Mele, A. (1997). Agency and mental action. Noûs, 31(11), 231-249.

Mele, A. (2009). Mental actions: A case study. In L. O’Brien \& M. Soteriou (Eds.), Mental actions. New York, NY: Oxford University Press.

Michaelin, K. (2011). Generative memory. Philosophical Psychology, 24, 323-343.

Nagel, T. (1974). What is it like to be a bat? Philosophical Review, 83, 435-450.

Nisbett, R. E., \& Wilson, T. D. (1977). Telling more than we can know: Verbal reports on mental processes. Psychological Review, 84, 231-250.

O’Brien, L., \& Soteriou, M. (Eds). (2009). Mental actions. New York, NY: Oxford University Press.

O'Connor, T., \& Sandis, C. (Eds). (2010). A companion to the philosophy of action. Oxford: Wiley-Blackwell.

Owens, D. (2009). Freedom and practical judgement. In L. O’Brien \& M. Soteriou (Eds.), Mental actions (pp. 121-237). New York, NY: Oxford University Press.

Peacocke, C. (1999). Being known. Oxford: Oxford University Press.

Peacocke, C. (2007). Mental action and self-awareness. In B. McLaughlin \& J. D. Cohen (Eds.), Contemporary debates in philosophy of mind. Oxford: Blackwell.

Proust, J. (2001). A Plea for mental acts. Synthese, 129(1), 105-128.

Proust, J. (2013). Philosophy of metacognition: Mental agency and self-awareness. Oxford: Oxford University Press.

Reyes, G., \& Sackur, J. (2014). Introspection during visual search. Consciousness and Cognition, 29, 212-229.

Reyes, G., \& Sackur, J. (2017a). Introspective access to implicit shifts of attention. Consciousness and Cognition, 48, 11-20.

Reyes, G., \& Sackur, J. (2017b). Introspection during short-term memory scanning. Quarterly Journal of Experimental Psychology, 1-13. https://doi.org/10.1177\% 2F1747021817738951

Ruben, D. (1995). Mental overpopulation and the problem of action. Journal of Philosophical Research, 20, 511-524.

Schneider, W. \& Shiffrin, R. (1977). Controlled and automatic human information processing: I. Detection, search, and attention. Psychological Review, 84, 1-66.

Searle, J. (1980). Minds, brains and programs. Behavioral and Brain Sciences, 3, 417-457.

Shepherd, J. (2015). Deciding as intentional action: Control over decisions. Australasian Journal of Philosophy, 93(2), 335-351.

Slagter, H., Lutz, A., Greischar, L. L., Francis, A. D., Nieuwenhuis, S., David, J. M., \& Dvidson, R. J. (2007). Mental training affects distribution of limited brain resources. PLoS Biology, 5, e138.

Soteriou, M. (2013). The mind's construction: The ontology of mind and mental action. Oxford: Oxford University Press.

Stocker, R. (1982). Responsibility especially for beliefs. Mind, 91, 398-417. 
Strawson, G. (2003). Mental ballistics or the involuntariness of spontaneity. Proceedings of the Aristotelian Society, 103, 227-256.

Upton, C. (2017). Meditation and the cultivation of virtue. Philosophical Psychology, 30, 373-397.

Valaris, M. (2017). What reasoning might be. Synthese, 194, 2007-2024. Advance online publication.

Van Vugt, M. K. (2015). Cognitive benefits of mindfulness meditation. In K. W. Brown, J. D. Creswell, \& R. M. Ryan (Eds.), Handbook of mindfulness: Theory, research, and practice (pp. 190-207). New York: Guilford Press.

Watzl, S. (2017). Structuring mind: The nature of attention and how it shapes consciousness. Oxford: Oxford University Press.

Wegner, D. M. (2002). The illusion of conscious will. Cambridge, MA: MIT Press.

Wegner, D. M., \& Wheatley, T. (1999). Apparent mental causation: Sources of the experience of will. American Psychologist, 54, 480-492.

$\mathrm{Wu}, \mathrm{W}$. (2013). Mental action and the threat of automaticity. In A. Clark, J. Kiverstein, \& T. Vierkant (Eds.), Decomposing the will (pp. 244-261). New York, NY: Oxford University Press. 